\title{
MEF2C-Related 5q14.3 Microdeletion Syndrome Detected by Array CGH: A Case Report
}

\author{
Jae Sun Shim, MD ${ }^{1}$, Kyunghoon Min, MD ${ }^{1}$, Seung Hoon Lee, MD ${ }^{1}$, Ji Eun Park, MS $^{2}$, \\ Sang Hee Park, $\mathrm{MS}^{2}$, MinYoung Kim, MD, $\mathrm{PhD}^{1}$, Sung Han Shim, MD, PhD $^{2,3}$ \\ ${ }^{1}$ Department of Rehabilitation Medicine, CHA Bundang Medical Center, CHA University, Seongnam; \\ ${ }^{2}$ Genetics Laboratory, Fertility Center of CHA Gangnam Medical Center, CHA University, Seoul; \\ ${ }^{3}$ Department of Biomedical Science, College of Life Science, CHA University, Pocheon, Korea
}

Genetic screening is being widely applied to trace the origin of global developmental delay or intellectual disability. The 5q14.3 microdeletion has recently been uncovered as a clinical syndrome presenting with severe intellectual disability, limited walking ability, febrile convulsions, absence of speech, and minor brain malformations. MEF2C was suggested as a gene mainly responsible for the $5 \mathrm{q} 14.3$ microdeletion syndrome. We present the case of a 6-year-old girl, who is the first patient in Korea with de novo interstitial microdeletions involving 5q14.3, showing the typical clinical features of 5q14.3 microdeletion syndrome with a smaller size of chromosomal involvement compared to the previous reports. The microdeletion was not detected by subtelomeric multiplex ligation-dependent probe amplification, but by array comparative genomic hybridization, which is advisable for the detection of a small-sized genetic abnormality.

Keywords Chromosomal aberrations, Developmental disabilities, 5q14.3 deletion

\section{INTRODUCTION}

Global developmental delay (GDD) and intellectual disability (ID) are major neurodevelopmental disorders in children. About $25 \%-50 \%$ of moderate to profound GDD/ID result from genetic etiology [1]. Among the possible aberrations in chromosomes, submicroscopic

Received July 15, 2014; Accepted August 25, 2014

Corresponding author: Sung Han Shim

Genetics Laboratory, Fertility Center of CHA Gangnam Medical Center, CHA University, 566 Nonhyeon-ro, Gangnam-gu, Seoul 135-913, Korea Tel: +82-2-3468-3443, Fax: +82-2-3468-2842, E-mail: shshim@cha.ac.kr

(c) This is an open-access article distributed under the terms of the Creative Commons Attribution Non-Commercial License (http://creativecommons. org/licenses/by-nc/4.0) which permits unrestricted noncommercial use, distribution, and reproduction in any medium, provided the original work is properly cited.

Copyright $\odot 2015$ by Korean Academy of Rehabilitation Medicine rearrangements including subtelomeric microdeletions or microduplications have been identified in GDD/IDD with detection rates ranging from $3 \%$ to $23 \%$ [2].

The 5q14.3 microdeletion syndrome has recently been recognized as a clinical syndrome, manifesting with severe intellectual disability, febrile seizures, muscular hypotonia, and minor brain anomalies [3]. The myocyte enhancer factor 2C gene (MEF2C), located in chromosome $5 \mathrm{q} 14.3$, is considered to be the gene mainly responsible for 5q14.3 microdeletion syndrome [4].

We present a patient with typical features of the $5 q 14.3$ microdeletion syndrome, which has not been reported in Korea yet.

\section{CASE REPORT}

A 6 years 7 months old female patient was born at full 
term following an uneventful pregnancy as the only child from healthy non-consanguineous parents. Her birth weight was $2,470 \mathrm{~g}$ (3rd centile), length was $46 \mathrm{~cm}$ (3rd centile), and occipital-frontal circumference was 32.5 $\mathrm{cm}$ (10-25th centile). She achieved head control in an erect position at 5 months and side-rolling at 7 months, showing a mild developmental delay. Despite having received physical and occupational therapy since the age of 8 months, she showed a GDD when we thoroughly reevaluated her developmental status at 6 years 4 months. All the domains including gross motor, fine motor, cognition, speech, and social behavior were severely delayed (Table 1). Climbing up the stairs alone or standing on one leg was impracticable. She also had problems in planning a series of movements. Fundamental sensory integration of vestibular, proprioceptive, and tactile stimuli were disrupted, leading to poor hand-eye coordination. She paid little attention to any linguistic stimuli, including calling her name, and could not recognize her family. Although there were some vocalizations, there was no meaningful expressive language observed, despite normal audiologic assessment findings. She was not toilet-trained and continued to use diapers. She had trunk hypotonia with mild cervicothoracic scoliosis (Fig. 1A), bilateral coxa valga (Fig. 1B), and pes planus (Fig. 1C). She had 6 febrile convulsions with partial seizures confirmed in an electroencephalography (EEG) at 5 years of age, but a followup EEG one year later showed no epileptiform activity. Both visual and brainstem auditory evoked potentials taken at 22 months were normal. Brain magnetic resonance imaging revealed delayed myelination at both 10 and 19 months (Fig. 2A, 2B), but no focal abnormality at 48 months (Fig. 2C). On ophthalmologic investigation, bilateral esotropia was observed, which required an early corrective surgery at 8 months. She had no prominent dysmorphism in her face except a broad forehead and mildly depressed nasal bridge.

Both chromosomal analysis of the proband and multiplex ligation-dependent probe amplification (MLPA) analysis using a subtelomeric probe set (P070) showed an apparently normal female karyotype (Fig. 3A, 3B). However, on an assessment with array comparative genomic hybridization (CGH), a microdeletion in the chromosomal 5q14.3 region (Fig. 3C) was detected. Both of her parents showed a normal hybridization pattern in that region (data were not shown). The deleted region was about $1332.682 \mathrm{~kb}$ in size, starting from 88031637 and ending at 89364319, and according to the ISCA database, it included only one known OMIM gene, MEF2C. The number of probes was 928 . The proband's karyotype was

Table 1. Clinical assessments of our patient

\begin{tabular}{|c|c|c|}
\hline Assessment & Result & Time of evaluation \\
\hline GMFCS & II & 6 yr 4 mo \\
\hline GMFM A\% (lying \& rolling) & 100 & \\
\hline GMFM B\% (sitting) & 100 & \\
\hline GMFM C\% (crawling \& kneeling) & 100 & \\
\hline GMFM D\% (standing) & 79 & \\
\hline GMFM E\% (walking \& running \& jumping) & 39 & \\
\hline GMFM total\% & 84 & \\
\hline BSID-II (mental) & $12 \mathrm{mo}$ & \\
\hline BSID-II (motor) & $14 \mathrm{mo}$ & \\
\hline K-WPPSI & $\mathrm{IQ}=0^{\mathrm{a})}$ & $5 \mathrm{yr} 11 \mathrm{mo}$ \\
\hline Vineland SMS & $\mathrm{SA}=1.47, \mathrm{SQ}=24.85$ & \\
\hline SELSI (receptive) & 8-9 mo & $29 \mathrm{mo}$ \\
\hline SELSI (expressive) & 6-7 mo & \\
\hline \multicolumn{3}{|c|}{$\begin{array}{l}\text { GMFCS, Gross Motor Function Classification Scale; BSID-II, Bayley Scales of Infant Development 2nd edition; K- } \\
\text { WPPSI, Korean-Wechsler Preschool and Primary Scale of Intelligence; Vineland SMS, Vineland Social Maturity Scale; } \\
\text { SELSI, Sequenced Language Scale for Infants; CARS, Childhood Autism Rating Scale; IQ, intelligence quotient; SA, } \\
\text { social age; SQ, social quotient. } \\
\text { a) The assessment was incomplete due to low cognition and poor compliance of the patient. }\end{array}$} \\
\hline
\end{tabular}



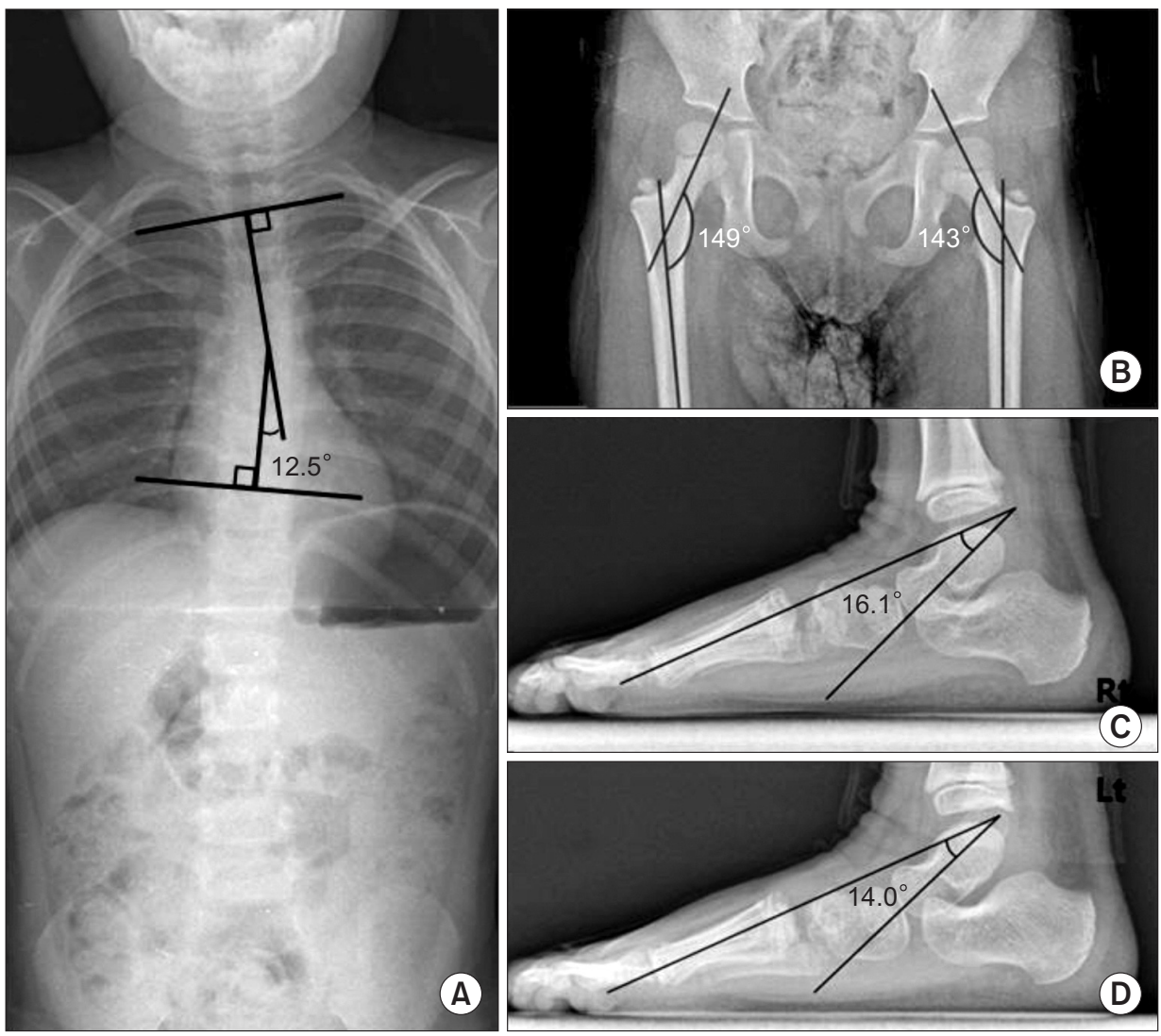

Fig. 1. Plain X-ray films of the patient showed mild thoracic scoliosis with Cobb's angle of $12.5^{\circ}$ (A), left pelvic tilting, bilateral coxa valga with the angle between the axis of femur neck and shaft

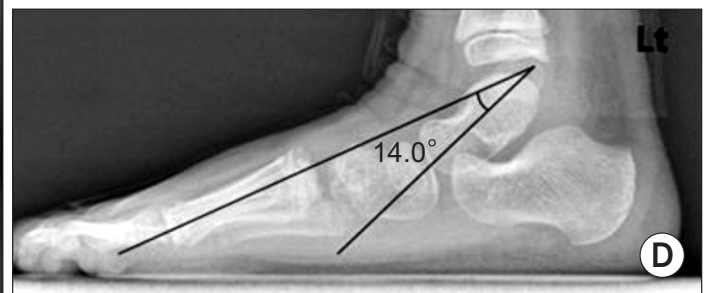
of $149^{\circ}$ and $143^{\circ}$, respectively (B), and bilateral pes planus of talometatarsal angle of $16.1^{\circ}(\mathrm{C})$ and $14.0^{\circ}(\mathrm{D})$. The patient was unable to stand still with her ankles in a neutral position while taking the plain X-rays.
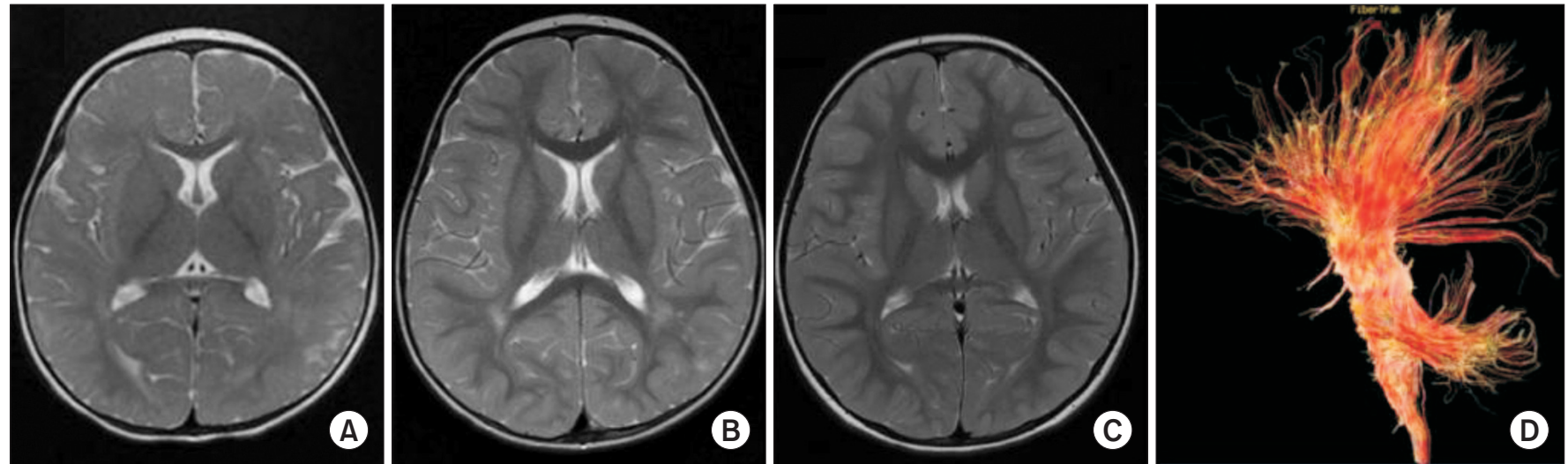

Fig. 2. Brain magnetic resonance imaging (MRI) of the patient showed delayed myelination at both 10 months (A) and 19 months (B), showing a prominent T2 high signal in the parietal deep white matter. A follow-up MRI at 48 months (C) had no focal abnormality. Diffusion tensor tractography showed normal microstructure (D).

46,XX.arr 5q14.3(88031637-89364319)x1 dn.

\section{DISCUSSION}

A $1.33-\mathrm{Mb}$ sized microdeletion in chromosome $5 \mathrm{q} 14.3$ region of our patient can be interpreted to be de novo, because such an aberration was not detected in the array
CGH of her parents.

MEF2C, located in 5q14.3, consists of 11 coding exons spreading along approximately $100 \mathrm{~kb}$ of genomic DNA [4]. MEF2C encodes a transcription factor, which belongs to the myocyte enhancer factor 2 subfamily, participating in the transmission of extracellular signals to the genome and in the activation of the genetic programs that control 
(A)

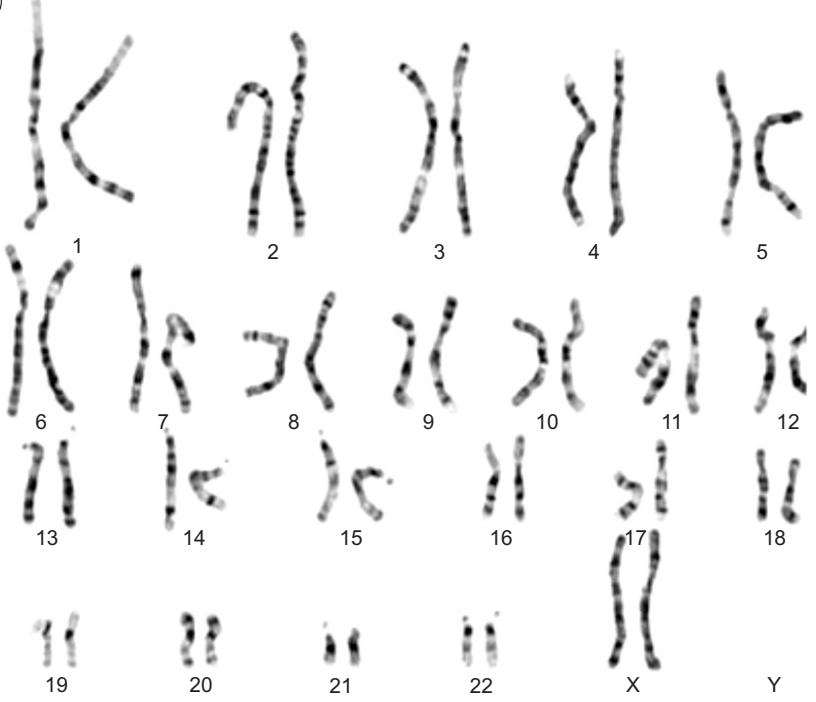

(B)

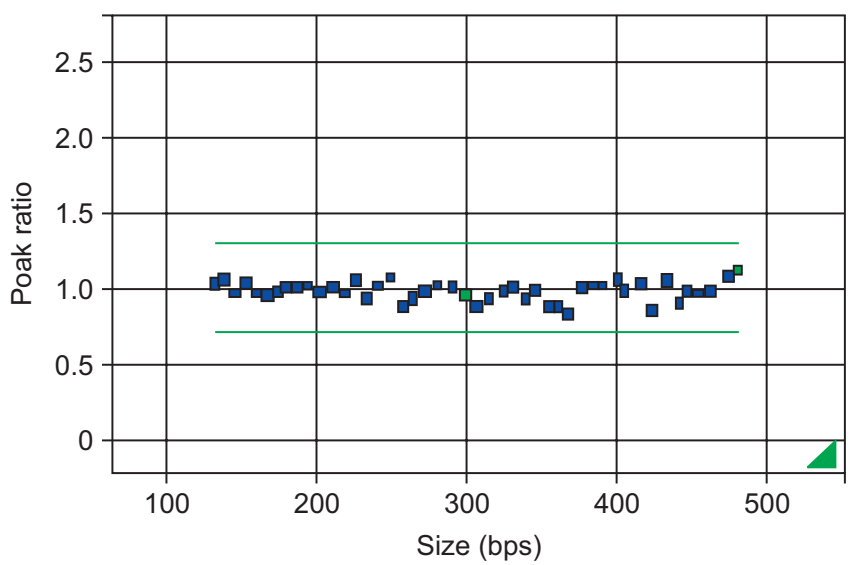

(C)

46, XX Normal female

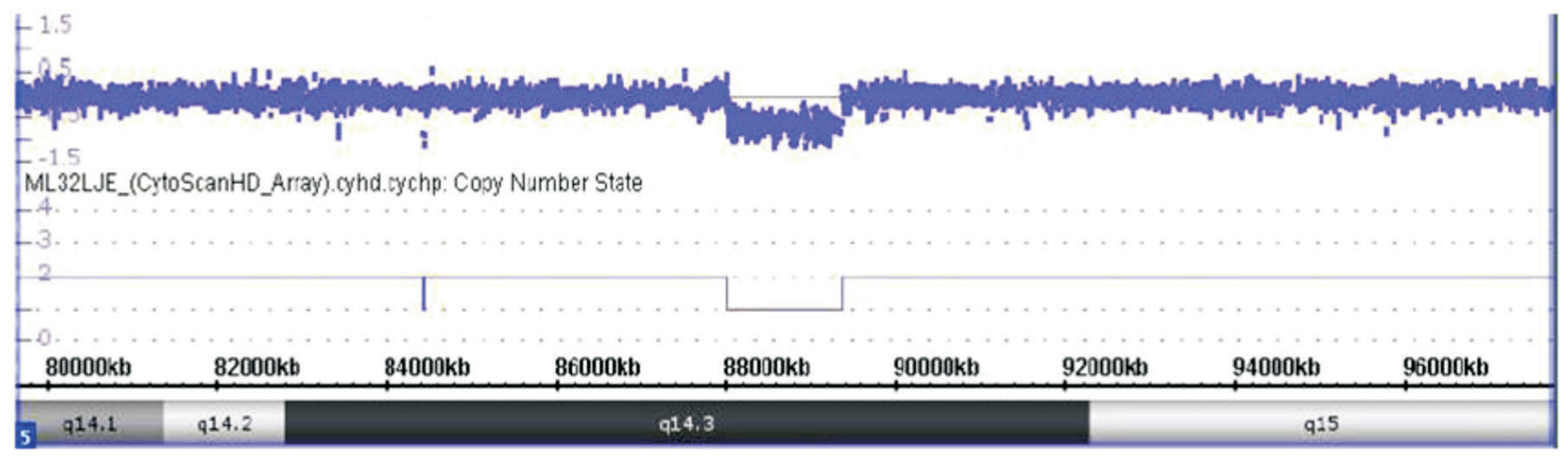

Fig. 3. Chromosome analysis of the proband (A) and multiplex ligation-dependent probe amplification analysis using a subtelomeric probe set (P070) (B) showed a normal female karyotype for our patient. However, the oligonucleotide array comparative genomic hybridization profile (C) showed a 1.33-Mb sized deletion in the $5 \mathrm{q} 14.3$ region.

cell differentiation, proliferation, morphogenesis, survival, and apoptosis of a wide range of cell types [5]. Due to $M E F 2 C$ 's involvement in many organs during various developmental stages, functional disruption of MEF2C results in a wide scope of detrimental effects throughout the course of development.

There have been 23 patients with 5 q14.3 deletions previously reported worldwide at present [6]. The clinical variability of these patients may be partly influenced by differences in the deletion's size [7]. However, despite having similar deletions in size, the severity of brain anomalies varies considerably from case to case. For example, Novara et al. [8] reported a patient (Fig. 4, P2 of Novara et al.) who had only a small deletion of $318 \mathrm{kbp}$, but showed severe perinatal hemorrhage and subsequent leukoencephalopathy.

Nowakowska et al. [7] reported that inclusion of MEF2C in the deleted segment is the most essential factor determining clinical features. In cases where $M E F 2 C$ is not involved, the chromosomal breakpoints were near the MEF2C. Shimojima et al. [6] insisted that the relative location of the deleted segment, that is, whether upstream or downstream of $M E F 2 C$, is important in the resulting clinical features and severity. Zweier et al. [4] suggested that genomic regions $233-\mathrm{kb}$ to $500-\mathrm{kb}$ upstream of $M E F 2 C$ may be required for proper $M E F 2 C$ expression. According to the Saitsu et al. [9], intellectual disability and earlyonset epilepsy are closely related to a disruption of the upstream region of $M E F 2 C$.

Compared to previously reported cases, our patient 


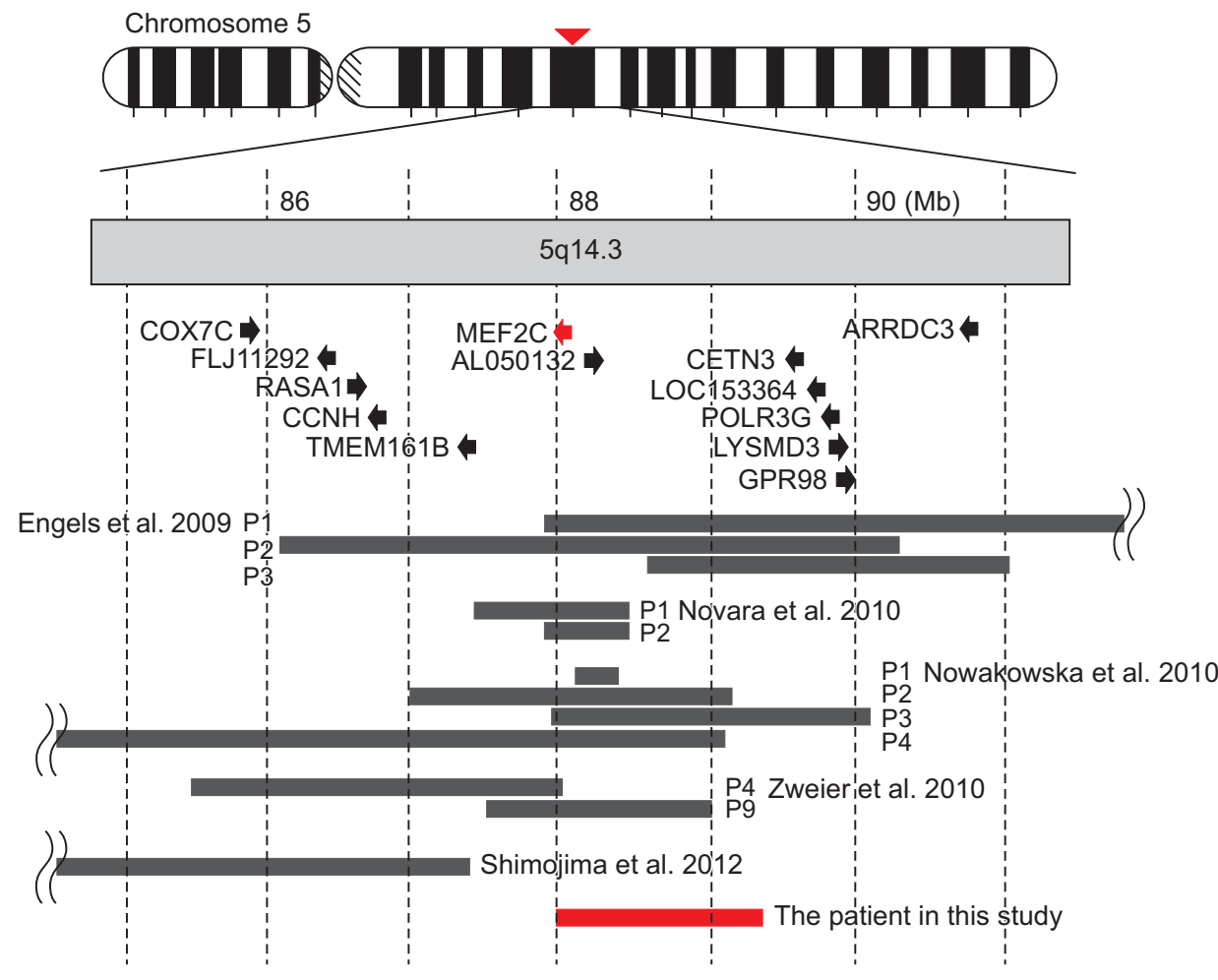

Fig. 4. Schematic representation of the deletions in chromosome $5 \mathrm{q} 14.3$ from all the previous reports (black bars) and our patient in this study (red bar). Black arrows represent the direction and the length of genes in this region. Modified from Shimojima et al. [6] with permission of John Wiley \& Sons.

had a relatively small-sized deletion, containing only one gene, $M E F 2 C$ (Fig. 4). The upstream region from $M E F 2 C$ was also included in the deleted segment. This result corresponds with previous research which considered $M E F 2 C$ to be the solely responsible gene for all the symptoms of 5 q14.3 deletion syndrome.

In this case, we were able to detect the genetic abnormality, not by subtelomeric MLPA or high resolution chromosome analysis, but only by array CGH. Array CGH has been widely used as a promising diagnostic method for patients with unexplained GDD/ID [10]. Array $\mathrm{CGH}$ can detect copy number variations (CNVs) as small as $1 \mathrm{~kb}$, which were recently considered to be the etiology of neurodevelopmental disorders including ID, GDD, autism, and schizophrenia [10]. Array CGH reliably identifies all known microdeletion and microduplication syndromes with additional information, including the exact location, size, and involved genes of the lesion, which may not be detected by conventional cytogenetic methods at all [11]. Thus, some researchers suggest array CGH should be the first-tier test prior to MLPA or G-band karyotyping in order to reduce the total cost of genetic testing, when patient does not present with features of a recognizable genetic syndrome or specific tests for a suspected disorder have been negative [11].

In conclusion, we reported the first patient in Korea with a 5q14.3 microdeletion in which MEF2C resided. By the aid of array CGH, we found the exact location and the size of chromosomal abnormality to establish the cause of the unexplained GDD/ID in this patient. This not only enabled us to make an early diagnosis and set up treatment strategies, but helped to obtain a deeper understanding of the role of MEF2C.

\section{CONFLICT OF INTEREST}

No potential conflict of interest relevant to this article was reported.

\section{ACKNOWLEDGMENTS}

This research was supported by Basic Science Research Program through the National Research Foundation of Korea (NRF), funded by the Ministry of Edu- 
cation Science and Technology (2012-0132 and NRF2013R1A1A3013182), Republic of Korea.

\section{REFERENCES}

1. Hunter AG. Outcome of the routine assessment of patients with mental retardation in a genetics clinic. Am J Med Genet 2000;90:60-8.

2. Szabo GP, Bessenyei B, Balogh E, Ujfalusi A, Szakszon $\mathrm{K}$, Olah E. Detection of subtelomeric chromosomal rearrangements in idiopathic mental retardation. Orv Hetil 2010;151:1091-8.

3. Engels H, Wohlleber E, Zink A, Hoyer J, Ludwig KU, Brockschmidt FF, et al. A novel microdeletion syndrome involving 5q14.3-q15: clinical and molecular cytogenetic characterization of three patients. Eur J Hum Genet 2009;17:1592-9.

4. Zweier M, Gregor A, Zweier C, Engels H, Sticht H, Wohlleber E, et al. Mutations in MEF2C from the $5 q 14.3 q 15$ microdeletion syndrome region are a frequent cause of severe mental retardation and diminish MECP2 and CDKL5 expression. Hum Mutat 2010;31:722-33.

5. Potthoff MJ, Olson EN. MEF2: a central regulator of diverse developmental programs. Development 2007;134:4131-40.

6. Shimojima K, Okumura A, Mori H, Abe S, Ikeno M,
Shimizu T, et al. De novo microdeletion of 5q14.3 excluding MEF2C in a patient with infantile spasms, microcephaly, and agenesis of the corpus callosum. Am J Med Genet A 2012;158A:2272-6.

7. Nowakowska BA, Obersztyn E, Szymanska K, Bekiesinska-Figatowska M, Xia Z, Ricks CB, et al. Severe mental retardation, seizures, and hypotonia due to deletions of MEF2C. Am J Med Genet B Neuropsychiatr Genet 2010;153B:1042-51.

8. Novara F, Beri S, Giorda R, Ortibus E, Nageshappa S, Darra F, et al. Refining the phenotype associated with MEF2C haploinsufficiency. Clin Genet 2010;78:471-7.

9. Saitsu H, Igarashi N, Kato M, Okada I, Kosho T, Shimokawa O, et al. De novo 5q14.3 translocation 121.5-kb upstream of MEF2C in a patient with severe intellectual disability and early-onset epileptic encephalopathy. Am J Med Genet A 2011;155A:2879-84.

10. Lee C, Iafrate AJ, Brothman AR. Copy number variations and clinical cytogenetic diagnosis of constitutional disorders. Nat Genet 2007;39(7 Suppl):S48-54.

11. Miller DT, Adam MP, Aradhya S, Biesecker LG, Brothman AR, Carter NP, et al. Consensus statement: chromosomal microarray is a first-tier clinical diagnostic test for individuals with developmental disabilities or congenital anomalies. Am J Hum Genet 2010;86:74964 . 